\title{
miR-155 as a Biomarker in B-Cell Malignancies
}

\author{
Hanne Due, ${ }^{1,2}$ Pernille Svendsen, ${ }^{1}$ Julie Støve Bødker, ${ }^{1}$ Alexander Schmitz, ${ }^{1}$ \\ Martin Bøgsted, ${ }^{1,3,4}$ Hans Erik Johnsen, ${ }^{1,4,5}$ Tarec Christoffer El-Galaly, ${ }^{1,4,5}$ \\ Anne Stidsholt Roug, ${ }^{2}$ and Karen Dybkær ${ }^{1,4}$
}

\author{
${ }^{1}$ Department of Haematology, Aalborg University Hospital, Hobrovej 18-22, 9100 Aalborg, Denmark \\ ${ }^{2}$ Department of Haematology, Aarhus University Hospital, Tage-Hansens Gade 2, 8000 Aarhus C, Denmark \\ ${ }^{3}$ Department of Mathematical Sciences, Aalborg University, Fredrik Bajers Vej 5, 9100 Aalborg, Denmark \\ ${ }^{4}$ Department of Clinical Medicine, Aalborg University, Fredrik Bajers Vej 5, 9100 Aalborg, Denmark \\ ${ }^{5}$ Clinical Cancer Research Center, Aalborg University Hospital, Hobrovej 18-22, 9100 Aalborg, Denmark
}

Correspondence should be addressed to Karen Dybkær; k.dybkaer@rn.dk

Received 23 December 2015; Accepted 3 April 2016

Academic Editor: Stefan Costinean

Copyright $\odot 2016$ Hanne Due et al. This is an open access article distributed under the Creative Commons Attribution License, which permits unrestricted use, distribution, and reproduction in any medium, provided the original work is properly cited.

\begin{abstract}
MicroRNAs have the potential to be useful biomarkers in the development of individualized treatment since they are easy to detect, are relatively stable during sample handling, and are important determinants of cellular processes controlling pathogenesis, progression, and response to treatment of several types of cancers including B-cell malignancies. miR-155 is an oncomiR with a crucial role in tumor initiation and development of several B-cell malignancies. The present review elucidates the potential of miR155 as a diagnostic, prognostic, or predictive biomarker in B-cell malignancies using a systematic search strategy to identify relevant literature. miR-155 was upregulated in several malignancies compared to nonmalignant controls and overexpression of miR-155 was further associated with poor prognosis. Elevated expression of miR-155 shows potential as a diagnostic and prognostic biomarker in diffuse large B-cell lymphoma and chronic lymphocytic leukemia. Additionally, in vitro and in vivo studies suggest miR-155 as an efficient therapeutic target, supporting its oncogenic function. The use of inhibiting anti-miR structures indicates promising potential as novel anticancer therapeutics. Reports from 53 studies prove that miR-155 has the potential to be a molecular tool in personalized medicine.
\end{abstract}

\section{Introduction}

Personalized medicine is a new principle that aims at tailoring medical treatment of the individual patients and thereby ending the current "one-fits-all" strategy. Today's cancer diagnostics are typically based on clinical findings, morphology, histology, cytogenetic, immune-phenotyping, and molecular genetic data, but still identification of the molecular pathways driving tumorigenesis often fails [1]. Different B-cell malignancies share common molecular pathways, which is why they may benefit from the same pathway-specific targeted treatment. Additionally, tumor subtypes within one disease entity can be characterized by distinct molecular pathogenesis markers as genetic aberrations or transcription phenotypic markers but still be treated alike causing inefficient expenditure treatment regardless of potential subgroup-specific treatment efficiency. The aim of personalized medicine is to drive the development of a more accurate classification of disease, defined by molecular pathogenesis ultimately enhancing diagnosis and treatment by the use of easy detectable biomarkers [2].

Biomarkers are defined as objective indicators of biological processes, pathogenic processes, or pharmacological response to a therapeutic intervention [3]. Diagnostic biomarkers identify the presence of disease and differentiate normal from malignant or distinguish different diagnoses or progression stages. Prognostic biomarkers provide information about clinical outcome for a class of patients when given a specific treatment, whereas predictive biomarkers provide information on how patients are expected to respond to a drug or treatment regimen. Most importantly, all biomarkers should add further information to present clinical tools. In 
TABLE 1: Cancer relevant target genes for miR-155 supported by experimental observations.

\begin{tabular}{llc}
\hline Target genes & $\begin{array}{l}\text { Main effect of aberrant miR-155 } \\
\text { expression }\end{array}$ & Reference \\
\hline SHIP1 & $\uparrow$ PI3K/AKT activity & {$[22,23]$} \\
& $\uparrow$ B-cell proliferation & \\
AID & $\begin{array}{l}\uparrow \text { immunoglobulin diversification/class } \\
\text { switch }\end{array}$ & {$[24]$} \\
PU.1 & $\begin{array}{l}\uparrow \text { immunoglobulin diversification/class } \\
\text { switch }\end{array}$ & {$[25]$} \\
HGAL & $\uparrow$ cell motility & {$[26]$} \\
C/EBP $\beta$ & $\uparrow$ B-cell proliferation & {$[23]$} \\
SMAD5 & $\uparrow$ evasion of TGF- $\beta$ 's growth inhibitory & {$[27]$} \\
FADD & effects & {$[28]$} \\
Ripk & $\downarrow$ apoptosis & {$[28]$} \\
SOCS1 & $\uparrow$ apoptosis & {$[29]$} \\
\hline
\end{tabular}

AID, activation-induced cytidine deaminase; $\mathrm{C} / \mathrm{EBP} \beta$, CCAAT/enhancerbinding protein $\beta$; FADD, Fas-Associated protein with Death Domain; HGAL, human germinal center-associated lymphoma; SHIP1, SH2 domain containing inositol $5^{\prime}$-phosphatase 1 ; SOCS1, suppressor of cytokine signaling protein 1 .

order to ensure accurate stratification, ideal biomarkers need to be easy to detect and provide both high sensitivity and specificity [4].

MicroRNAs (miRNAs) have been demonstrated to possess biomarker potential in multiple diseases [5], both individually and when combined in signature profiles [6-9]. miRNAs are short noncoding RNAs of 20-22 nucleotides that function to regulate gene expression at the posttranscriptional level. They play fundamental roles in the regulation of cellular proliferation, differentiation, and apoptosis [10]. miRNAs are deregulated in many types of cancer, including B-cell malignancies, where they can function as oncogenes, favoring initiation and progression of cancers, or as tumor suppressors, preventing tumorigenesis $[11,12]$. One of the most widely studied miRNAs in B-cell malignancies is the oncogenic miR-155, transcribed from a noncoding RNA BIC (B-cell Integration Cluster). miR-155 biogenesis is only briefly summarized since it has recently been extensive and thoroughly reviewed by others $[13,14]$. At normal physiologic conditions, miR-155 is a crucial player in hematopoiesis, the immune response, and inflammation [15-18]. It has been found to be upregulated in several types of cancers [19] and has shown specific importance in the pathogenesis of $\mathrm{B}$ cell malignancies. The oncogenic function of miR-155 can be explained by its target genes and the involved underlying molecular pathways presented in Table 1. Overexpression of miR-155 in mice results in development of lymphoproliferative diseases, while subsequent withdrawal leads to remission [20]. Thus, miR-155 is suggested to be a future treatment target. A high number of studies have investigated its potential as a biomarker in several B-cell malignancies, though conflicting results have been presented. To elaborate and assess the potential of miR-155 as a diagnostic, prognostic, and predictive biomarker or target of novel treatments in
B-cell malignancies as a part of personalized medicine, we systematically reviewed the existing literature.

\section{Materials and Methods}

This review was prepared according to the Preferred Reporting for Systematic Reviews and Meta-Analyses (PRISMA) Guidelines [21].

2.1. Literature Search. PubMed and EMBASE were systematically searched for eligible articles. The search terms used in both databases are provided in Table S1 in Supplementary Material available online at http://dx.doi.org/10.1155/2016/ 9513037. The search was finalized on November 18, 2015. Additional studies were identified by scanning reference lists of articles. The screening process was performed by two reviewers by reading titles and abstracts, while the eligibility of full-texts was assessed in the same manner.

2.2. Inclusion and Exclusion Criteria. Studies were included in the analysis if fulfilling the following inclusion criteria: (1) concerning miR-155 expression as a biomarker or target of chemotherapeutic treatment, (2) focusing on B-cell malignancies, (3) analyzing patient samples, (4) original research articles or letters, and (5) results published in English. Articles were excluded if the present disease was reported in $\leq 2$ independent studies.

2.3. Analysis. Data concerning the specific disease, cohort size, sample type, study design of miRNA selection, analytical method, and outcome was extracted manually, and studies were grouped according to the investigated biomarker properties of miR-155 (i.e., diagnostic, prognostic, and/or predictive). Studies exploiting miR-155 as a therapeutic target were described according to their methods (e.g., in vitro/in vivo), outcomes, and impact of their findings.

\section{Results}

The systematic search revealed 606 articles, which were screened by reading title and abstract. A total of 126 fulltexts were assessed, and 53 of these studies were included in the review, presented in Figure S1. All included articles were published in peer-reviewed scientific journals. Fortyeight of the included articles investigated the expression of miR-155 as either a diagnostic, prognostic, or predictive tool in the management of several diseases, though we excluded studies of specific diseases represented by two or less papers. Five papers exploited miR-155 as a potential target in the treatment of B-cell malignancies. As presented in Table 2, the diagnostic potential of deregulated miR-155 expression has been widely investigated in diffuse large B-cell lymphoma (DLBCL), Burkitt's lymphoma (BL), Hodgkin's lymphoma (HL), mucosa-associated lymphoid tissue lymphoma (MALT), follicular lymphoma (FL), splenic marginal zone lymphoma (SMZL), and chronic lymphatic leukemia (CLL). Additionally, the prognostic potential of miR-155 has been investigated in several studies of DLBCL and CLL, whereas the predictive potential has not been thoroughly 
TABLE 2: miR-155 as diagnostic biomarker in B-cell malignancies.

\begin{tabular}{|c|c|c|c|c|c|c|c|}
\hline Disease & Sample type & Cohort & & Initial miRNA selection & Method & Expression & Ref \\
\hline DLBCL & FFPE & $\begin{array}{l}90 \text { DLBCL cases } \\
31 \text { controls }\end{array}$ & & Previous research & RT-qPCR & $\uparrow$ & {$[32]$} \\
\hline \multirow{2}{*}{ DLBCL } & CS & $\begin{array}{l}75 \text { DLBCL cases } \\
10 \text { controls }\end{array}$ & $\mathrm{T}$ & \multirow{2}{*}{ Global screening } & Microarray & $\uparrow$ & \multirow[b]{2}{*}[46]{} \\
\hline & FFPE & $\begin{array}{l}47 \text { DLBCL cases } \\
15 \text { controls }\end{array}$ & $\mathrm{V}$ & & RT-qPCR & $\uparrow$ & \\
\hline \multirow[b]{2}{*}{ DLBCL } & \multirow{2}{*}{ Blood } & $\begin{array}{l}20 \text { DLBCL cases } \\
20 \text { controls }\end{array}$ & $\mathrm{T}$ & \multirow[b]{2}{*}{ Previous research } & \multirow[b]{2}{*}{ RT-qPCR } & $\uparrow$ & \multirow[b]{2}{*}{ [37] } \\
\hline & & $\begin{array}{l}75 \text { DLBCL cases } \\
77 \text { controls }\end{array}$ & $\mathrm{V}$ & & & $\uparrow$ & \\
\hline \multirow{2}{*}{ DLBCL } & \multirow{2}{*}{ FFPE } & $\begin{array}{l}80 \text { DLBCL cases } \\
12 \text { controls }\end{array}$ & & \multirow{2}{*}{ Global screening } & \multirow{2}{*}{ Microarray } & $\uparrow$ & \multirow[b]{2}{*}[33]{} \\
\hline & & $\begin{array}{l}80 \text { DLBCL cases } \\
18 \text { FL cases }\end{array}$ & & & & NS & \\
\hline DLBCL & FFPE & $\begin{array}{l}11 \text { PCNSL cases } \\
10 \text { nDLBCL cases }\end{array}$ & & Previous research & RT-qPCR & $\uparrow$ & [47] \\
\hline \multirow[b]{2}{*}{ DLBCL } & \multirow{2}{*}{ CS, FFPE } & $\begin{array}{l}35 \text { DLBCL cases } \\
12 \text { controls }\end{array}$ & & \multirow[b]{2}{*}{ Global screening } & \multirow[b]{2}{*}{ RT-qPCR } & $\uparrow$ & \multirow[b]{2}{*}{ [34] } \\
\hline & & $\begin{array}{l}35 \text { DLBCL cases } \\
27 \text { FL cases }\end{array}$ & & & & NS & \\
\hline \multirow{2}{*}{ DLBCL } & \multirow{2}{*}{ CS, FFPE } & 18 DLBCL cases & & \multirow{2}{*}{ Previous research } & RNA-ISH & $\uparrow$ & \multirow{2}{*}[48]{} \\
\hline & & 5 controls & & & RT-qPCR & $\uparrow$ & \\
\hline \multirow[b]{2}{*}{ DLBCL } & CS & $\begin{array}{l}29 \text { DLBCL cases } \\
12 \text { BL cases }\end{array}$ & $\mathrm{T}$ & \multirow{2}{*}{ Global screening } & Microarray & $\uparrow$ & \multirow{2}{*}[38]{} \\
\hline & FFPE & $\begin{array}{l}43 \text { DLBCL cases } \\
28 \text { BL cases }\end{array}$ & $\mathrm{V}$ & & RT-qPCR & $\uparrow$ & \\
\hline DLBCL & Blood & $\begin{array}{l}60 \text { DLBCL cases } \\
43 \text { controls }\end{array}$ & & Previous research & RT-qPCR & $\uparrow$ & {$[35]$} \\
\hline DLBCL & FFPE & $\begin{array}{l}19 \text { DLBCL cases } \\
31 \text { exN DLBCL cases }\end{array}$ & & Previous research & RT-qPCR & NS & [49] \\
\hline DLBCL & CS & $\begin{array}{l}22 \text { DLBCL cases } \\
7 \text { controls }\end{array}$ & & Previous research & RT-qPCR & $\uparrow$ & {$[50]$} \\
\hline DLBCL & CS & $\begin{array}{l}79 \text { DLBCL cases } \\
36 \text { BL cases }\end{array}$ & & Global screening & Microarray & $\uparrow$ & [39] \\
\hline DLBCL & CS & $\begin{array}{l}23 \text { DLBCL cases } \\
2 \text { controls }\end{array}$ & & Previous research & RT-qPCR & $\uparrow$ & {$[51]$} \\
\hline \multirow[b]{2}{*}{ DLBCL } & \multirow{2}{*}{ FNAB } & $\begin{array}{l}45 \text { DLBCL cases } \\
33 \text { BL cases }\end{array}$ & & \multirow[b]{2}{*}{ Previous research } & \multirow[b]{2}{*}{ RT-qPCR } & $\uparrow$ & \multirow[b]{2}{*}[40]{} \\
\hline & & $\begin{array}{l}45 \text { DLBCL cases } \\
19 \text { DLBCL/BL cases }\end{array}$ & & & & $\uparrow$ & \\
\hline DLBCL & FFPE & $\begin{array}{l}200 \text { DLBCL cases } \\
11 \text { controls }\end{array}$ & & Previous research & RT-qPCR & $\uparrow$ & {$[52]$} \\
\hline DLBCL & CS & $\begin{array}{l}10 \text { DLBCL EBV - cases } \\
11 \text { DLBCL EBV+ cases }\end{array}$ & & Global screening & $\begin{array}{l}\text { Sequencing } \\
\text { RT-qPCR }\end{array}$ & $\begin{array}{c}\uparrow \\
\text { NS }\end{array}$ & {$[53]$} \\
\hline DLBCL & FFPE & $\begin{array}{l}58 \text { DLBCL cases } \\
7 \text { controls } \\
58 \text { DLBCL cases } \\
46 \text { FL cases }\end{array}$ & & Global screening & RT-qPCR & $\begin{array}{c}\uparrow \\
\text { NS }\end{array}$ & {$[36]$} \\
\hline DLBCL & Ocular fluid & $\begin{array}{l}17 \text { retinal DLBCL cases } \\
12 \text { uveitis cases }\end{array}$ & & Global screening & RT-qPCR & $\downarrow$ & {$[54]$} \\
\hline $\mathrm{BL}$ & CS & $\begin{array}{l}6 \mathrm{BL} \\
\text { DLBCL (cell line) }\end{array}$ & & Previous research & RT-qPCR & $\downarrow$ & {$[55]$} \\
\hline
\end{tabular}


TABle 2: Continued.

\begin{tabular}{|c|c|c|c|c|c|c|c|}
\hline Disease & Sample type & Cohort & & Initial miRNA selection & Method & Expression & Ref \\
\hline $\mathrm{BL}$ & $\begin{array}{l}\text { FFPE } \\
\text { CS }\end{array}$ & $\begin{array}{l}3 \text { BL cases } \\
2 \text { controls }\end{array}$ & & Previous research & Northern blot & $\downarrow$ & {$[56$} \\
\hline $\mathrm{BL}$ & CS & $\begin{array}{l}11 \text { BL cases } \\
11 \text { controls }\end{array}$ & & Previous research & RT-qPCR & $\downarrow$ & {$[57]$} \\
\hline $\mathrm{BL}$ & CS & $\begin{array}{l}12 \text { BL cases } \\
135 \text { other } L\end{array}$ & & Global screening & Microarray & $\downarrow$ & {$[38]$} \\
\hline HL & FFPE & $\begin{array}{l}42 \text { HL cases } \\
8 \text { controls }\end{array}$ & & Global screening & $\begin{array}{l}\text { Microarray } \\
\text { RT-qPCR }\end{array}$ & $\begin{array}{l}\text { NS } \\
\text { NS }\end{array}$ & {$[58]$} \\
\hline HL & CS & $\begin{array}{l}25 \text { HL cases } \\
7 \text { controls }\end{array}$ & & Previous research & RT-qPCR & $\uparrow$ & {$[50]$} \\
\hline HL & CS, FFPE & $\begin{array}{l}5 \text { HL cases } \\
5 \text { controls }\end{array}$ & & Previous research & RT-qPCR & NS & {$[48]$} \\
\hline MALT & CS & $\begin{array}{l}22 \text { MALT cases } \\
46 \text { controls }\end{array}$ & & Previous research & RT-qPCR & $\uparrow$ & [59] \\
\hline & CS & $\begin{array}{l}4 \text { MALT cases } \\
4 \text { controls }^{*}\end{array}$ & $\mathrm{~T}$ & & Microarray & $\uparrow$ & \\
\hline MALT & $\cos$ & $\begin{array}{l}14 \text { MALT cases } \\
14 \text { controls }^{*}\end{array}$ & $\mathrm{~V}$ & Global screening & RT-qPCR & $\uparrow$ & {$[60]$} \\
\hline & CS & $\begin{array}{l}3 \text { MALT cases } \\
3 \text { controls }^{*}\end{array}$ & $\mathrm{~T}$ & & Microarray & $\uparrow$ & \\
\hline MALT & $\cos$ & $\begin{array}{l}20 \text { MALT cases } \\
20 \text { controls* }^{*}\end{array}$ & $\mathrm{~V}$ & Global screening & RT-qPCR & $\uparrow$ & {$[61]$} \\
\hline $\mathrm{FL}$ & $\mathrm{BM}$ & $\begin{array}{l}5 \text { FL cases } \\
3 \text { controls }\end{array}$ & & Previous research & RT-qPCR & NS & {$[62]$} \\
\hline SMZL & FFPE & $\begin{array}{l}15 \text { SMZL cases } \\
11 \text { controls }\end{array}$ & & Global screening & RT-qPCR & $\uparrow$ & [63] \\
\hline & CS & $\begin{array}{l}31 \text { SMZL cases } \\
15 \text { controls }\end{array}$ & $\mathrm{T}$ & & Microarray & $\uparrow$ & \\
\hline SMZL & FFPE & $\begin{array}{l}77 \text { SMZL cases } \\
6 \text { controls }\end{array}$ & $\mathrm{V}$ & Global screening & RT-qPCR & $\uparrow$ & {$[64]$} \\
\hline & & 15 SMZL cases & & & Microarray & $\uparrow$ & \\
\hline SMZL & FFPE & 9 controls & & Global screening & RT-qPCR & $\uparrow$ & {$[65]$} \\
\hline CLL & CS & $\begin{array}{l}70 \text { CLL cases } \\
18 \text { controls }\end{array}$ & & Previous research & RT-qPCR & $\uparrow$ & {$[66]$} \\
\hline CLL & Blood & $\begin{array}{l}6 \text { CLL cases } \\
3 \text { controls }\end{array}$ & & Global screening & Microarray & $\uparrow$ & [67] \\
\hline CLL & Blood & $\begin{array}{l}7 \text { CLL cases } \\
4 \text { controls }\end{array}$ & & Previous research & Northern blot & $\uparrow$ & {$[68]$} \\
\hline & & 69 CLL cases & & & Nanostring & $\uparrow$ & \\
\hline CLL & Blood & 15 controls & & Global screening & RT-qPCR & $\uparrow$ & [69] \\
\hline CLL & Blood & $\begin{array}{l}113 \text { CLL cases } \\
7 \text { controls }\end{array}$ & & Previous research & RT-qPCR & $\uparrow$ & {$[70]$} \\
\hline & & 50 CLL cases & & & Microarray & $\uparrow$ & \\
\hline CLL & Blood & 14 controls & & Global screening & RT-qPCR & $\uparrow$ & {$[71]$} \\
\hline CLL & Blood & $\begin{array}{l}38 \text { CLL cases } \\
9 \text { controls }\end{array}$ & & Global screening & Microarray & $\uparrow$ & {$[72]$} \\
\hline CLL & Blood & $\begin{array}{l}56 \text { CLL cases } \\
7 \text { controls }\end{array}$ & & Previous research & RT-qPCR & $\uparrow$ & {$[73]$} \\
\hline
\end{tabular}


TABLE 2: Continued.

\begin{tabular}{|c|c|c|c|c|c|c|c|}
\hline Disease & Sample type & Cohort & & Initial miRNA selection & Method & Expression & Ref \\
\hline \multirow{2}{*}{ CLL } & \multirow{2}{*}{ Blood } & $\begin{array}{l}70 \text { CLL cases } \\
8 \text { controls }\end{array}$ & $\mathrm{T}$ & \multirow{2}{*}{ Previous research } & RT-qPCR & $\uparrow$ & \multirow[b]{2}{*}[74]{} \\
\hline & & $\begin{array}{l}23 \text { CLL cases } \\
12 \text { controls }\end{array}$ & $\mathrm{V}$ & & RT-qPCR & $\uparrow$ & \\
\hline
\end{tabular}

Disease: DLBCL, diffuse large B-cell lymphoma; BL, Burkitt’s lymphoma; HL, Hodgkin lymphoma; MALT, mucosa-associated lymphoid tissue; FL, follicular lymphoma; SMZL, splenic marginal zone lymphoma; CLL, chronic lymphocytic leukemia. Sample type: FFPE, formalin-fixed paraffin-embedded tissue samples; CS, clinical samples; FNABs, fine needle aspirations. Cohort: controls, nonmalignant tissues; PCNSL, primary CNS lymphoma; nDLBCL, nodal DLBCL; exN DLBCL, extranodal DLBCL; EBV, Epstein-Barr virus; L, lymphoma; control* , adjacent normal tissue, T; training set; V, validation set. Method: RTqPCR, reverse transcription quantitative PCR; RNA-ISH, RNA in situ hybridization. Expression: $\uparrow$, increased; $\downarrow$, decreased; NS, not significant. Ref: reference.

studied. Hence, the following report will primarily focus on DLBCL and CLL, as the biomarker potential of miR-155 has been reported more extensively in these malignancies. Malignancies represented by few conflicting studies are not discussed further in the review.

3.1. Diffuse Large B-Cell Lymphoma. DLBCL is a highly aggressive disease representing a clinically, morphologically, and genetically heterogeneous group of non-Hodgkin lymphomas. Despite the treatment improvements by inclusion of rituximab, up to $40 \%$ of the patients eventually die from relapsing or refractory disease [30, 31]. In general, detection of precancerous lesions and early stage cancers is crucial to reducing the disease mortality. Early detection of DLBCL may likewise permit treatment of early stages, which can prevent disease-related deaths. Thus, it is necessary to identify new diagnostic biomarkers for clinical use. Through the systematic search, we found 18 studies focusing on the expression of miR-155 as a diagnostic marker in DLBCL, presented in Table 2. All studies comparing the expression level in DLBCL patients to healthy controls found a significant upregulation of miR-155 in DLBCL. The mean fold-change values span from 3 to 19 [32-36] and Fang et al. reported a cutoff value of 0.0022 and a sensitivity and specificity at $83 \%$ and $65 \%$, respectively [37]. Distinction between nonHodgkin lymphomas, such as DLBCL, FL, and BL, can be difficult due to great molecular and clinical heterogeneity. In addition to the need for early detection, new biomarkers should also improve the accuracy of lymphoma diagnosis and decisions of therapeutics. Three studies found miR155 higher expressed in DLBCL compared to BL patients illustrating miR-155 as a potential diagnostic biomarker [3840]. However, studies comparing DLBCL and FL showed no significant differential expression $[33,34,36]$. Blood samples were analyzed in two studies $[35,37]$ and frozen tumor tissue and FFPE tissue in the remaining.

Using gene-expression profiling, DLBCL can be divided into the two molecular subtypes: germinal center B-cell-like (GCB) and activated B-cell-like (ABC) [41, 42]. The subtypes present different clinical outcome with GCB patients having a 5-year survival rate of $60 \%$ compared to $35 \%$ for those patients with ABC DLBCL [43]. In order to simplify and make accessible in a routine clinical setting, the molecular subtype identification has been implemented in several centers by the use of immunohistochemical (IHC) analysis resulting in DLBCL subtyping into GCB/non-GCB or $\mathrm{GCB} / \mathrm{ABC}[42,44,45]$. In this systematic review, we identified 15 articles evaluating the prognostic impact of miR155 , of which 13 studied the correlation between miR-155 and the molecular subtypes (Table 3). miR-155 was upregulated in the $\mathrm{ABC}$ subtype in nine studies while the remaining three did not find significant differential expression between the subgroups. Since patients classified as ABC exhibit an adverse prognosis, miR-155 holds the potential as prognostic marker.

Conflicting results were found in studies investigating the association of miR-155 expression and clinical outcome. Zhong et al. stratified patients according to high or low expression of miR-155 with a cutoff value at 3.98 and sensitivity and specificity value at $80 \%$ and $58.5 \%$, respectively [32]. High miR-155 expression was significantly associated with adverse prognosis, which was also reported by Iqbal et al. using similar expression level stratification [39]. Zhong et al. further demonstrated that miR-155 and the international prognostic index (IPI) were statistically significant independent prognostic factors [32]. Contradictorily, other studies found that miR-155 expression did not correlate with DLBCL outcome [36, 49, 75]. Surprisingly, Jung and Aguiar observed that high expression of miR-155 was associated with improved prognosis exclusively within the $\mathrm{ABC}$ subgroup [75]. Zhong et al. showed predictive potential of miR155, where patients treated with CHOP (cyclophosphamide, doxorubicin, vincristine, and prednisone) were compared to a cohort of R-CHOP (addition of rituximab) treated patients [32]. Interestingly, high expression of miR-155 improved clinical outcome in patients treated with R-CHOP compared to CHOP. This difference was not seen in patients with low miR-155 expression, suggesting that miR-155 has the potential to guide treatment with rituximab [32]. Additionally, Iqbal et al. reported that high miR-155 expression significantly correlated with R-CHOP treatment failure, suggesting a potential role as predictive biomarker [39]. This finding was supported by in vitro studies showing that high miR-155 expression sensitizes cells to synthetic Akt inhibitors, suggesting a novel treatment option for resistant DLBCL patients [39].

3.2. Chronic Lymphocytic Leukemia. CLL is characterized by clonal proliferation of mature B-cells accumulating in the peripheral blood, bone marrow, lymph nodes, and spleen [76]. Despite its prevalence, no cure exists and patients are treated with various chemotherapeutic drugs at the presence of progressive or symptomatic disease [76]. Several studies investigated the expression level of miR-155 in samples from 
TABLE 3: miR-155 as prognostic biomarker in diffuse large B-cell lymphoma (DLBCL), its expression in relation to GCB or nGCB/ABC subtyping, and direct relation to prognosis.

\begin{tabular}{|c|c|c|c|c|c|c|c|c|}
\hline \multirow{2}{*}{ Cohort } & \multirow{2}{*}{$\begin{array}{l}\text { Molecular } \\
\text { subtype }\end{array}$} & \multirow[b]{2}{*}{ Sample type } & \multirow{2}{*}{$\begin{array}{l}\text { Initial miR } \\
\text { selection }\end{array}$} & \multirow[b]{2}{*}{ Method } & \multicolumn{3}{|c|}{ Outcome } & \multirow[b]{2}{*}{ Ref } \\
\hline & & & & & Prognosis & Measure & $\begin{array}{l}\text { Molecular } \\
\text { subtype }\end{array}$ & \\
\hline \multirow[t]{9}{*}{$\begin{array}{l}90 \text { DLBCL } \\
(51 / 39) \\
\end{array}$} & $\begin{array}{l}21 \mathrm{GCB} \\
69 \mathrm{nGCB}\end{array}$ & FFPE & Previous research & RT-qPCR & $\uparrow$ poor & $\mathrm{RA}, \mathrm{OR}$ & $\uparrow \mathrm{nGCB}$ & {$[32]$} \\
\hline & $\begin{array}{l}20 \mathrm{GCB} \\
34 \mathrm{nGCB} \\
\end{array}$ & FFPE & Global screening & RT-qPCR & & & $\uparrow \mathrm{nGCB}$ & {$[46]$} \\
\hline & $\begin{array}{l}32 \mathrm{GCB} \\
28 \mathrm{nGCB} \\
\end{array}$ & FFPE & Global screening & Microarray & & & $\uparrow \mathrm{nGCB}$ & {$[33]$} \\
\hline & $\begin{array}{l}9 \mathrm{GCB} \\
12 \mathrm{nGCB}\end{array}$ & FFPE & Previous research & RT-qPCR & & & NS & {$[47]$} \\
\hline & $\begin{array}{l}85 \mathrm{GCB} \\
34 \mathrm{ABC} \\
\end{array}$ & CS & Previous research & Microarray & & & $\uparrow \mathrm{ABC}$ & [89] \\
\hline & $\begin{array}{l}17 \mathrm{GCB} \\
18 \mathrm{ABC}\end{array}$ & CS, FFPE & Global screening & RT-qPCR & & & $\uparrow \mathrm{ABC}$ & {$[34]$} \\
\hline & $\begin{array}{l}11 \mathrm{GCB} \\
7 \mathrm{ABC}\end{array}$ & CS, FFPE & Previous research & $\begin{array}{l}\text { ISH } \\
\text { RT-qPCR }\end{array}$ & & & $\uparrow \mathrm{ABC}$ & {$[48]$} \\
\hline & $\begin{array}{l}9 \mathrm{GCB} \\
9 \mathrm{nGCB}\end{array}$ & FFPE & Previous research & $\begin{array}{l}\text { ISH } \\
\text { Microarray }\end{array}$ & & & NS & {$[90]$} \\
\hline & $\begin{array}{l}8 \mathrm{GCB} \\
15 \mathrm{nGCB}\end{array}$ & CS & Previous research & RT-qPCR & & & NS & {$[50]$} \\
\hline \multirow[t]{2}{*}{$\begin{array}{l}54 \text { DLBCL } \\
(27 / 27) \\
\end{array}$} & $\begin{array}{l}32 \mathrm{GCB} \\
27 \mathrm{ABC}\end{array}$ & CS & Global screening & Microarray & $\uparrow$ poor & EFS & $\uparrow \mathrm{ABC}$ & {$[39]$} \\
\hline & $\begin{array}{l}4 \mathrm{GCB} \\
19 \mathrm{ABC}\end{array}$ & CS & Previous research & RT-qPCR & & & $\uparrow \mathrm{ABC}$ & {$[51]$} \\
\hline $\begin{array}{l}129 \mathrm{DLBCL} \\
24 \mathrm{ABC}\end{array}$ & & CS & Previous research & & $\begin{array}{l}\text { NS } \\
\uparrow \text { improved }\end{array}$ & $\begin{array}{l}\text { PFS, OS } \\
\text { PFS, OS }\end{array}$ & & [75] \\
\hline \multirow[t]{2}{*}{$53 \mathrm{DLBCL}$} & $\begin{array}{l}25 \mathrm{GCB} \\
25 \mathrm{nGCB} \\
\end{array}$ & FFPE & Previous research & RT-qPCR & NS & EFS, OS & $\uparrow \mathrm{nGCB}$ & {$[36]$} \\
\hline & $\begin{array}{l}14 \mathrm{GCB} \\
36 \mathrm{nGCB} \\
\end{array}$ & FFPE & Previous research & RT-qPCR & & & NS & {$[49]$} \\
\hline $\begin{array}{l}200 \text { DLBCL } \\
(121 / 79) \\
\end{array}$ & & FFPE & Previous research & & NS & PFS, OS & & {$[52]$} \\
\hline
\end{tabular}

( / ) in column 1: number of patients with high and low miR-155 expression; numbers in column 2 indicate how many DLBCL patients included for miR-155 expression evaluation in each molecular subtype; subtype: GCB, germinal center B-cell-like; nGCB, non-GCB; ABC, activated B-cell-like. Sample type: FFPE, formalin-fixed paraffin-embedded tissue samples; CS, clinical samples. Method: RT-qPCR, reverse transcription quantitative PCR; ISH, in situ hybridization. Prognosis: $\uparrow$, increased expression; $\downarrow$, decreased expression; NS, not significant. Outcome measure: RA, response assessment; OR, overall response; EFS, eventfree survival; PFS, progression-free survival; OS, overall survival. Ref: reference.

CLL patients as compared to healthy controls, Table 2. Interestingly, none of these studies aimed at establishing new diagnostic tools but focused on elaborating the molecular pathogenesis of the disease or use preliminary diagnostic signatures of deregulated miRNAs to single out potential prognostic biomarkers. In all studies and irrespective of the analytical technique, miR-155 was upregulated in CLL compared to healthy controls. A few studies reported a mean fold-change of miR-155 expression in the range of 2-5, while individual samples showed great varying fold-changes [67, 69-71].

The prognostic potential of miR-155 expression in CLL was studied more extensively and showed varying results, as presented in Table 3. Particularly, favorable factors showed conflicting associations with miR-155 expression. CLL is usually described by many different prognostic factors, such as clinical staging systems (Rai and Binet), somatic hypermutation of the immunoglobulin heavy chain variable region (IgHV), surface CD38 expression, expression of zetaassociated protein 70 (ZAP-70), or chromosomal abnormalities (17p, 13q, 11q, and trisomy 12) [76]. Relating miR-155 expression to the individual prognostic factors revealed no correlation. However, studies often focused on different prognostic factors, making concise comparisons and conclusions impossible. In patients with $17 \mathrm{p}$ deletion, the expression of miR-155 was either upregulated or nonsignificantly differentiated between groups $[77,78]$. miR-155 was overexpressed in both studies investigating 11q deletions, though patients with trisomy 12 had either downregulated or unaffected expression $[66,77]$. ZAP-70 expression was related to the upregulation of 
miR-155 in two studies, while there was no association in four other studies [72-74, 79-81]. miR-155 was either downregulated or unaffected in patients with IgHV mutations $[68,71-$ $74,79-81$, while $13 q$ deletions were associated with high, low, and unaffected expression levels $[66,71,77,82]$. Thus, the studies generally showed no specific correlation between miR-155 expression and favorable (13q deletion and IgHV mutation) or unfavorable (17p, 11q deletion, trisomy 12 and ZAP-70 expression) prognostic factors.

When the elevated expression of miR-155 was directly correlated with survival data, high expression was not consistently associated with poor prognosis. However, studies used different outcome measures, complicating the assessment of the prognostic potential of miR-155. Furthermore, studies failed to report specific treatment regimens and treatment homogeneity of their cohorts. Ferrajoli et al. investigated the survival of CLL patients stratified according to high or low plasma miR-155 expression in two different cohorts [74]. One cohort received treatment with the FCR regimen (fludarabine, cyclophosphamide, and rituximab), while the other cohort received single agent treatment with lenalidomide. High miR-155 expression was in both cohorts associated with poor treatment outcome estimated by clinical response assessment (RA) [74]. According to Lawrie et al. patients relapsing after treatment with fludarabine and rituximab either with or without alemtuzumab showed poor progression-free survival (PFS) when stratified according to high miR-155 expression [66]. It was further shown that monitoring miR-155 expression after treatment with ibrutinib could be an indicator of treatment failure. The expression of miR-155 decreased upon treatment, and patients whose expression rose above baseline during follow-up were prone to experience disease relapse [66].

Predictive biomarker potential of miR-155 has not been directly investigated, yet detection of 17 p deletions by miR-155 as a surrogate marker could guide treatment decisions. Today, patients with $17 \mathrm{p}$ deletions are treated more aggressively due to poor prognostic results of front-line treatment with FCR [83]. As mentioned above, high miR-155 expression was associated with treatment failure in FCR and lenalidomide treated patients, suggesting potential use of miR-155 as a predictive biomarker [74].

3.3. Mucosa-Associated Lymphoid Tissue (MALT). Extranodal marginal zone lymphomas (MALT lymphomas) are rare, low-grade B-cell lymphomas of mucosa-associated lymphoid tissue. Expression of miR-155 in MALT was found elevated in three out of three eligible studies [59-61]. Thorns et al. reported a stepwise increase in miR-155 expression from benign to malignant lymphoepithelial lesions [59]. Gastric MALT can be associated with chronic inflammation triggered by infection with Helicobacter pylori (H. pylori). Antibiotic treatment leads to complete remission in $60-80 \%$ of the patients; however improved identification of nonresponsive patients is needed to guide treatment [84]. The study by Saito et al. observed that resistant patients had a higher miR-155 level than cases showing complete remission, suggesting the potential of miR-155 as a predictive indicator [61].
3.4. Splenic Marginal Zone Lymphoma (SMZL). SMZL is a rare form of small B-cell malignancy infiltrating the spleen, bone marrow, and peripheral blood. Three studies reported increased expression of miR-155 in diseased samples compared to controls [63-65]. Peveling-Oberhag et al. found a fold-change of miR-155 of 2.8 [63]. Additionally, Arribas et al. showed significantly increased miR-155 expression in SMZL spleen samples compared to nonmalignant samples from reactive spleens [64]. In contrast, the expression of miR155 was downregulated in SMZL samples compared to spleens infiltrated by FL, CLL, and mantle cell lymphoma, though this change was not significant [64].

3.5. $m i R-155$ as a Therapeutic Target. Due to the oncogenic function of miR-155 in especially B-cell malignancies, miR155 holds potential as a target for future therapeutic interventions, exploited by five studies, Figure 1. Chemically modified synthetic oligonucleotides are efficient inhibitors of miRNAs in vitro and in vivo, improving systemic stability and binding affinity of the anti-miRNA $[85,86]$. They bind the miRNA structure by complementary hybridization, preventing the miRNA from binding to its target mRNA. Usually, synthetic oligonucleotides such as PNA (peptide nucleic acid) and LNA (locked nucleic acid) are used. These RNA/DNA analogues are constructed by changing the nucleic acid backbone structures, and studies have proven their efficient inhibition of miR-155 in vitro in murine B-cells and patientderived CLL and Waldenstrom cell lines $[85,86]$. Anti-miR155 exposure resulted in decreased cell proliferation and survival of the CLL and Waldenstrom cells [85]. Evaluation of the systemic stability and efficacy was investigated in wild type mice and Waldenstrom xenografts $[85,86]$. miR155 expression was completely inhibited in the spleen upon injection of PNA anti-miR-155 in wild type mice [86]. Zhang et al. examined the distribution and intracellular uptake of fluorescence marked LNA anti-miR-155 in hematopoietic organs in wild type mice and Waldenstrom xenografts [85]. The anti-miR-155 was successfully delivered to cells in these specific organs. Additionally, anti-miR-155 intravenous administration resulted in decreased tumor burden in the Waldenstrom xenografts [85].

Drawbacks of systemic delivery are related to biological stability in the organism and intracellular uptake of the anti-miR. Babar et al. exploited the use of a nanoparticlebased delivery system of anti-miR-155 in a transgenic mouse model overexpressing miR-155 [20]. The nanoparticle encapsulated the anti-miR-155 structure to aid its stability and delivery. Additionally, coating of the nanoparticle with cellpenetrating peptides improved the intracellular uptake of anti-miR-155 in vivo [20].

In order to use anti-miR-155 as therapeutics, challenges regarding nonspecific organ distribution have to be overcome. miR-155 is constitutively expressed in several tissues and has a crucial role in the function of the immune system $[16,17]$. Thus, tumor specific distribution is warranted to avoid disruption of normal immunologic function, causing critical side effects. Cheng et al. showed a novel model for tumor specific distribution, utilizing tumor environment 


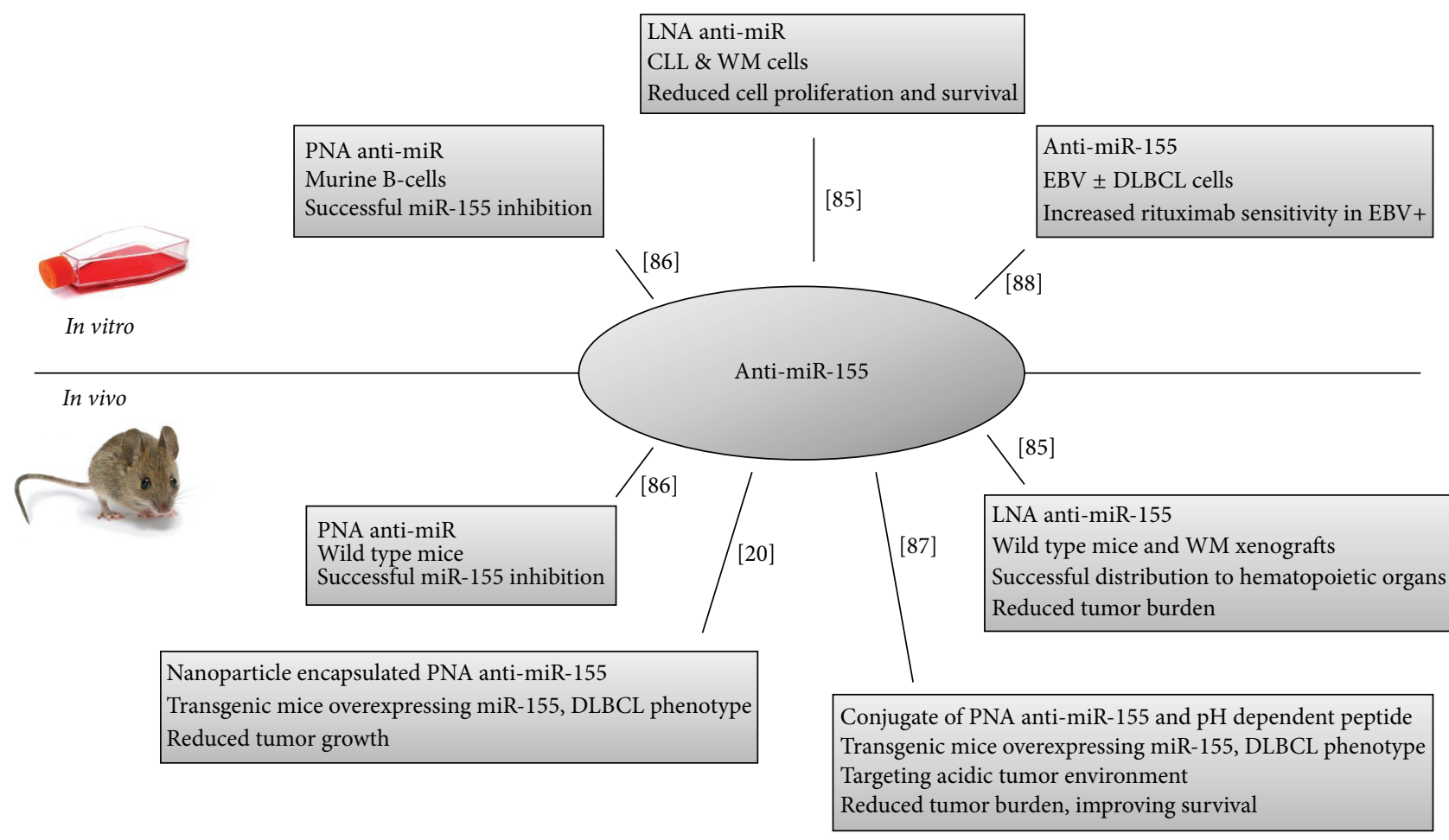

FIgURE 1: Studies $(n=5)$ exploiting miR-155 as a therapeutic target using anti-miR-155 structures. PNA, peptide nucleic acid; LNA, locked nucleic acid; CLL, chronic lymphocytic leukemia; WM, Waldenstrom macroglobulinemia; DLBCL, diffuse large B-cell lymphoma; EBV+, Epstein-Barr virus positive; EBV-, Epstein-Barr virus negative.

acidity, a hallmark of cancer [87]. They developed a conjugate of the anti-miR-155 structure and a $\mathrm{pH}$-induced transmembrane structure peptide. The peptide has the ability to localize the acidic tumor microenvironment and at low $\mathrm{pH}$, the peptide forms an inducible transmembrane helix promoting translocation of impermeable molecules across the cell membrane. Hereby the anti-miR-155 is efficiently delivered into the tumor cells causing reduced cell viability. Using the same miR-155 overexpressing transgene mice as Babar et al., the mice spontaneously developed lymphoma progressing from follicular hyperplasia to DLBCL. Administration of the antimiR- 155 conjugate at the time of tumor manifestation resulted in reduced tumor volume, suppressed metastatic spread of neoplastic cells, and improved survival compared to controls. High-dose administration to healthy mice showed absence of systemic toxicity, including maintenance of normal liver and kidney function [87]. Thus, this study introduces a novel model for using anti-miR as anticancer drug, having great impact on both targeted drug delivery and personalized medicine, since individual miR-155 expression levels are easily measured.

As mentioned, resistance to therapy is observed in $40 \%$ of patients with DLBCL and consequently, novel treatment options for resistant patients are needed [31]. Iqbal et al. reported treatment failure of $\mathrm{R}-\mathrm{CHOP}$ in patients with high miR-155 expression and suggested Akt inhibitors as alternative therapeutics, since miR-155 activates this specific pathway [39]. The effect of Akt inhibitors was investigated in Epstein-Barr virus positive $(\mathrm{EBV}+)$ cell lines by Kim et al. [88]. Initially they found EBV+ cell lines to be resistant toward rituximab, having a phosphorylated Akt pathway, and simultaneous overexpression of miR-155. Akt inhibitors restored the sensitivity toward rituximab, and anti-miR155 significantly reduced the cell survival upon rituximab exposure [88]. Thus, both Akt inhibitors and anti-miR-155 hold potential as add-on drugs to increase the response of DLBCL patients treated with R-CHOP.

3.6. Targets of miR-155. To understand how miR-155 act and identify the underlying molecular mechanisms driving tumorigenesis, many studies have investigated the target genes, of which some are listed in Table 1. Identification of targets and the involved pathways is important since it puts the biomarker into molecular perspective and additionally is crucial to understanding of the underlying molecular effects of using anti-miR-155 as an antineoplastic drug.

miR-155 was reported to target $S H I P 1$ and $C / E B P \beta$, which are two important inhibitors of the IL-6 signaling pathway. Downregulation of these genes blocks B-cell differentiation and causes an improved cell survival due to activation of PI3K/Akt and MAPK pathway [22, 23]. Additionally, by targeting $H G A L$, a lymphocyte motility inhibitor, miR155 promotes cell migration, which could contribute to a more aggressive disease [26]. Overexpression of miR-155 also leads to downregulation of SMAD5, a modulator of TGF$\beta$ signaling. miR-155 overexpression renders DLBCL cells resistant to growth inhibitory effects of TGF- $\beta$ and BMP via defective p21 induction and impaired cell cycle arrest [27]. 
TABLE 4: miR-155 as prognostic biomarker in CLL, its expression in relation to established prognostic factors, and direct relation to prognosis.

\begin{tabular}{|c|c|c|c|c|c|c|c|c|c|}
\hline \multirow{2}{*}{$\begin{array}{l}\text { Cohort } \\
\text { CLL }\end{array}$} & & \multirow[b]{2}{*}{ Sample type } & \multirow[b]{2}{*}{$\begin{array}{l}\text { Initial miR } \\
\text { selection }\end{array}$} & \multirow[b]{2}{*}{ Method } & \multicolumn{4}{|c|}{ Outcome $^{*}$} & \multirow[b]{2}{*}{ Ref } \\
\hline & & & & & $\begin{array}{l}\text { Unfavorable } \\
\text { factors }\end{array}$ & $\begin{array}{l}\text { Favorable } \\
\text { factors }\end{array}$ & Prognosis & Measure & \\
\hline \multicolumn{2}{|l|}{70} & CS & $\begin{array}{l}\text { Previous } \\
\text { research }\end{array}$ & RT-qPCR & $\uparrow$ & $\uparrow$ & & & {$[66]$} \\
\hline \multicolumn{2}{|l|}{$109(56 / 53)$} & CS & \multirow{2}{*}{$\begin{array}{l}\text { Previous } \\
\text { research }\end{array}$} & \multirow{2}{*}{ nCounter } & \multirow[t]{2}{*}{$\uparrow$} & \multirow[t]{2}{*}{$\downarrow$} & & $\begin{array}{l}\text { OS } \\
\text { PFS }\end{array}$ & \multirow{2}{*}[79]{} \\
\hline $9(4 / 5)$ & & Blood & & & & & $\uparrow$ poor & Relapse & \\
\hline $8(4 / 4)$ & & Blood & $\begin{array}{l}\text { Previous } \\
\text { research }\end{array}$ & Northern blot & & NS & & & {$[68]$} \\
\hline $43(18 / 25)$ & & Blood & $\begin{array}{l}\text { Previous } \\
\text { research }\end{array}$ & RT-qPCR & NS & NS & & & {$[70]$} \\
\hline 70 & $\mathrm{~T}$ & \multirow{2}{*}{ Blood } & \multirow{2}{*}{$\begin{array}{l}\text { Global } \\
\text { screening }\end{array}$} & Microarray & & $\uparrow$ & & & \multirow{2}{*}{ [91] } \\
\hline 24 & $\mathrm{~V}$ & & & RT-qPCR & & $\uparrow$ & & & \\
\hline \multicolumn{2}{|l|}{$70(33 / 37)$} & $\begin{array}{l}\text { FFPE } \\
\text { Blood }\end{array}$ & $\begin{array}{l}\text { Previous } \\
\text { research }\end{array}$ & RT-qPCR & NS & NS & & & {$[80]$} \\
\hline \multicolumn{2}{|l|}{50} & Blood & $\begin{array}{l}\text { Global } \\
\text { screening }\end{array}$ & Microarray & NS & NS & & & {$[71]$} \\
\hline \multicolumn{2}{|l|}{143} & \multirow[t]{2}{*}{ Blood } & \multirow[t]{2}{*}{$\begin{array}{l}\text { Previous } \\
\text { research }\end{array}$} & \multirow[t]{2}{*}{ RT-qPCR } & \multirow[t]{2}{*}{ NS } & \multirow[t]{2}{*}{ NS } & & $\begin{array}{l}\text { RA } \\
\text { OS }\end{array}$ & \multirow[t]{2}{*}[74]{} \\
\hline $85(31 / 45)$ & & & & & & & $\uparrow$ poor & RA & \\
\hline $86(55 / 31)$ & $\mathrm{T}$ & \multirow{2}{*}{ Blood } & \multirow{2}{*}{$\begin{array}{l}\text { Previous } \\
\text { research }\end{array}$} & RT-qPCR & $\uparrow$ & $\downarrow$ & $\uparrow$ poor & TFS & \multirow{2}{*}[81]{} \\
\hline $181(95 / 86)$ & $\mathrm{V}$ & & & Microarray & $\uparrow$ & $\downarrow$ & $\uparrow$ poor & TFS & \\
\hline 94 & $\mathrm{~T}$ & \multirow{2}{*}{ CS } & \multirow{2}{*}{$\begin{array}{l}\text { Global } \\
\text { screening }\end{array}$} & \multirow{2}{*}{ Microarray } & $\uparrow$ & & $\uparrow$ poor & TIT & \multirow[b]{2}{*}[92]{} \\
\hline 50 & $\mathrm{~V}$ & & & & $\uparrow$ & & & & \\
\hline 61 & $\mathrm{~T}$ & & Global & Microarray & $\uparrow$ & $\downarrow$ & & & \\
\hline 29 & $\mathrm{~V}$ & CS & screening & RT-qPCR & $\uparrow$ & $\downarrow$ & & & [77] \\
\hline $104(64 / 40)$ & & Blood & $\begin{array}{l}\text { Previous } \\
\text { research }\end{array}$ & RT-qPCR & $\uparrow$ & & NS & $\begin{array}{l}\text { OS } \\
\text { PFS }\end{array}$ & {$[78]$} \\
\hline 56 & & Blood & $\begin{array}{l}\text { Previous } \\
\text { research }\end{array}$ & RT-qPCR & NS & NS & & & [73] \\
\hline 28 & & Blood & $\begin{array}{l}\text { Global } \\
\text { screening }\end{array}$ & Microarray & NS & NS & NS & TIT & {$[72]$} \\
\hline
\end{tabular}

Cohort: T, training set; V, validation set. Sample type: CS, clinical sample; FFPE, formalin-fixed paraffin-embedded tissue samples. Method: RT-qPCR, reverse transcription quantitative PCR. Outcome: ${ }^{*}$ unfavorable factors: 17p deletion, 11q deletion, trisomy $12, \mathrm{CD} 38^{+}$cells, ZAP-70 expression $>20 \%$, and/or advanced disease stage determined by either Rai or Binet. Favorable factors: normal karyotype, IgHV mutations, and/or 13q deletion [76]; $\uparrow$, increased expression; $\downarrow$, decreased expression; NS, not significant. Outcome measure: OS, overall survival; PFS, progression-free survival; RA, response assessment; TFS, treatment-free survival; TI, time to initial treatment. Ref: reference.

The two death domain containing genes FADD and Ripkl are also identified as target genes of miR-155. It is thus reasonable to assume that miR-155 targeting of these transcripts could lead to antiapoptotic effects [28].

\section{Discussion}

This review identified a total of 53 studies addressing the potential of miR-155 as putative biomarker or as a therapeutic target in B-cell malignancies. The results, presented in Tables 2,3 , and 4, display that miR-155 expression may function as a valuable tool in both diagnosis and prognostic evaluation of DLBCL patients and having prognostic impact in CLL as the results showed consistency across multiple studies. Few studies reported diagnostic potential of miR-155 expression in MALT, SMZL, FL, and HL. However, based on the limited number of studies and samples included in those, the significance needs reconfirmation in independent studies using larger cohorts.

The results of miR-155 as diagnostic marker of DLBCL were very consistent and independent of sample type, cohort size, and methodology. High expression of miR-155 enables stratification of DLBCL patients from healthy controls and BL patients, supporting its potential as a diagnostic tool. In contrast, lack of accuracy in differentiating DLBCL from FL patients was observed. This systematic review also presents evidence that miR-155 expression is associated with DLBCL molecular subtypes, even though some studies did not find 
a significant differential expression [47, 49, 50, 90]. Cohort sizes varied considerably across studies and generally the larger the cohort, the more valid the result. Studies reporting nonsignificant results stand out with small cohorts exemplified by Fischer et al. having 21 patients included compared to the cohort of 90 in the study by Zhong et al. [32, 47]. Another important matter that makes the studies less comparable is the fact that the subtype classification of the DLBCL patients into $\mathrm{GCB}$ and non-GCB/ABC is performed by $\mathrm{IHC}$ analysis using different staining strategies and interpretation algorithms. Additionally, IHC is difficult to standardize due to variation between laboratories, such as sample handling, antibodies utilized, and observers.

The most surprising observation was made by Jung and Aguiar, finding miR-155 overexpression association with improved outcome in ABC DLBCL [75]. The reason for this association is not immediately clear; however, they suggest that action of target genes contributes to the findings. Noteworthily, only 24 ABC patients are stratified into low or high miR-155 expression illustrating the need to expand and validate the data in order to trust the information [75].

miR-155 was significantly upregulated in all studies comparing CLL cases to healthy controls, indicating diagnostic potential. However, CLL is easily diagnosed in clinical cases from blood analysis, arguing against the need of a novel diagnostic biomarker for this disease [83]. miR-155 as prognostic marker in CLL is not unambitious. However, an association of miR-155 expression and favorable prognostic factors differed greatly between studies. This could be due to the individual different factors investigated such as specific deletions and mutations. Noteworthily, studies failed to report the specific treatment regimens giving potential bias because the prognosis is dependent on the effectiveness of the treatment. In addition, if patients did not receive the same treatment, the studies are less comparable. In general, high miR-155 expression was often associated with more aggressive disease and poor prognosis, though not significant across all studies. Ultimately, miR-155 expression was not consistently sufficient in stratifying CLL patients according to individual prognostic factors. In contrast, elevated miR-155 expression as an independent factor was associated with poor clinical outcome across studies, suggesting its potential as a direct prognostic biomarker in CLL.

Considering the fact that miR-155 is an oncomiR [11], the findings of high expression in the poor prognostic ABC subtype and the adverse prognostic impact of miR155 expression on survival in DLBCL are consistent and in accordance with the observed association of high expression and more aggressive disease in CLL.

When analyzing the findings, it is also important to consider differences in methodology. Initial global microarray screenings were performed in several studies; however, they were not based on the same microarray models giving variations in the miRNA covering probes. The other widely used method is RT-qPCR which is based on another technique and relies on probes other than those used in microarray detection. The fold-change and accuracy of the studies therefore cannot be directly compared across studies but concordance of upregulated miR-155 and pure outcome independent of platform supports the robustness of the association. In several studies, a training cohort is utilized to identify miR-155 as potential diagnostic or prognostic tool and subsequently a validation cohort is analyzed to test and validate the result, increasing the significance of the findings. Others exploit the same cohort but validate the result using a different detection technique. Both approaches strengthen the observations and make the findings more valid.

Different sample types have potential to cause conflicting results. Studies regarding diagnostic evaluation of miR-155 in DLBCL analyze blood samples, formalin-fixed/paraffinembedded tissues, and frozen tissues; however, no inconsistency is observed, indicating stable expression and robust detection of miR-155 despite sample types, preparation, and storage. Each sample type has different advantages. FFPE tissue samples are the most abundant available archival material and miRNA can successfully be isolated from processed formalin-fixed material, due to miRNAs relative resistance toward RNase degradation. Using RT-qPCR and microarray analysis, similar results of miRNA expression are found in FFPE and frozen material [93]. Lawrie et al. and Fang et al. studied miR-155 expression in blood samples to investigate the potential as noninvasive biomarker [35, 37]. Search for noninvasive biomarkers for diagnosis, prognosis, and monitoring of cancers has long been the goal of clinical research.

A guideline for Strengthening the Reporting of Observational studies in Epidemiology-Molecular Epidemiology (STROBE-ME) has been proposed, though several studies included in this review failed to report their investigations thoroughly (e.g., sample types, storage, and handling). Additionally, the studies included in this review differed in their aims, outcomes measures, and methods, complicating the general comparison of the studies and rendering a statistical meta-analysis impossible. The validity of this systematic review is improved by the fact that PRISMA guidelines are met and that the search strategy encompassed MESH/ENTRY terms and free text words.

Introducing new potential biomarkers into the clinic holds great difficulties and challenges. Therefore, the Early Detection Research Network (EDRN) has suggested a systematic approach guiding the process of biomarker development similar to the clinical stages of drug development [94]. Phase 1 includes preclinical investigations, where tumor tissue is compared to healthy controls in order to identify differential characteristics. A clinical biomarker assay is developed and tested in phase 2, including evaluation of the biomarkers ability to distinguish subjects with cancer from those without cancer. Phase 3 is a retrospective investigation of the biomarkers ability to detect presence of disease before it is clinically diagnosed, whereas phase 4 evaluates biomarker properties in a prospective follow-up study. Finally, phase 5 evaluates whether the biomarker and early diagnosis improved the overall benefit for the screened population. Although the guideline focuses on developing diagnostic biomarkers, the structure is potentially valuable for prognostic and predictive biomarkers as well. All included diagnostic studies of CLL were consistent with phase 1 investigations, though as mentioned before a new diagnostic 
biomarker of CLL would hold limited clinical use. In addition, prognostic investigations of miR-155 in CLL could be described as phase 1 investigations, where a biomarker assay and assessment are still missing. Studies reporting miR-155 as potential diagnostic biomarker of DLBCL are all on the early phases of diagnostic biomarker development as well, which is why clinical implementation will require further studies at higher developmental phases. Only Fang et al. reported evaluation of miR-155's ability to distinguish DLBCL patients from healthy controls [37]. Thus, miR-155 cannot be considered as a diagnostic biomarker in clinical use at short term.

In order to implement the concept of personalized medicine, new molecular biomarkers need to be established to improve early diagnosis, patient stratification according to high-risk patients, and predictions of treatment response. According to the present assessment, miR-155 could hold potential as a novel diagnostic biomarker in several B-cell malignancies, including DLBCL and CLL. However, miR-155 still needs to move through the remaining biomarker developmental steps and evaluations before its potential use can be fully exploited. However, one important disadvantage of miR155 as a diagnostic biomarker is that it is overexpressed not only in one specific malignancy but also in several, complicating diagnostic discriminations of the different malignancies. Noteworthily, an important advantage is the validated target genes of miR-155, which puts the biomarker into perspectives of molecular pathways.

Elevated miR-155 expression was generally associated with poor survival in both CLL and DLBCL, showing independent prognostic impact, though as a marker for the present prognostic tools (e.g., chromosomal subtyping and $\mathrm{ABC} / \mathrm{GCB}$ ) it did not add further information. In general, prognostic biomarkers only hold beneficial information, if nonresponsive patients can be treated differently. The biomarker then moves from prognostic to predictive, where it can be used to guide treatment choices. No thorough investigations have been reported of miR-155 as a predictive biomarker, though its prognostic observations could imply the need for new treatment options for patients with a high expression level. Akt inhibitors (currently in clinical trials [95]) have been suggested as efficient therapeutics for the treatment of patients with high miR-155 expression, since miR-155 activates this pathway. Logically, other novel treatments could evidently be anti-miRNAs suppressing the miR-155 expression and its oncogenic function. Their effect has been proved both in vitro and in vivo, and a targeted distribution model strengthens the potential as a novel therapeutic. At the present time, new clinical phase I trial of cutaneous $\mathrm{T}$ cell lymphoma (CTCL) investigates the safety and tolerability of anti-miR-155 (MRG-106) [96]. Presumably, this treatment might show interesting potential in DLBCL and CLL patients as well. Noteworthily, miravirsen, antimiR-122, was the first microRNA targeted drug ever to reach clinical trials in 2009, for the management of hepatitis C viral infection [97]. Interestingly, miR-122 was later shown to be overexpressed in CTCL, suggesting that inhibition of miR-122 might also be a promising strategy in improving treatment outcome in these patients [98].

\section{Conclusion}

In summary, the expression of miR-155 shows potential as a diagnostic and prognostic biomarker, though further studies are warranted to assess its use in treatment prediction. Interestingly elevated expression was generally associated with poor treatment response, which is why it has been investigated and evidenced as an efficient therapeutic target. These properties prove that miR-155 has the potential to be a molecular tool in personalized medicine, bringing us one step closer to improvements of diagnosis and treatment.

\section{Disclosure}

Hanne Due and Pernille Svendsen shared first authorship.

\section{Competing Interests}

The authors declare that they have no competing interests.

\section{Authors' Contributions}

Hanne Due and Pernille Svendsen contributed equally to this paper.

\section{Acknowledgments}

The authors would like to extend their gratitude to the Medical Library at Aalborg University Hospital, Denmark, for assistance in the search process, and the Medical Specialist, Heinrich Kopp's Grant, who provided funding for the project.

\section{References}

[1] E. Campo, S. H. Swerdlow, N. L. Harris, S. Pileri, H. Stein, and E. S. Jaffe, "The 2008 WHO classification of lymphoid neoplasms and beyond: evolving concepts and practical applications," Blood, vol. 117, no. 19, pp. 5019-5032, 2011.

[2] National Research Council (US) Committee on a Framework for Developing a New Taxonomy of Disease, Toward Precision Medicine: Building a Knowledge Network for Biomedical Research and a New Taxonomy of Disease, National Academies Press (US), Washington, DC, USA, 2011.

[3] Biomarkers Definitions Working Group, "Biomarkers and surrogate endpoints: preferred definitions and conceptual framework," Clinical Pharmacology \& Therapeutics, vol. 69, no. 3, pp. 89-95, 2001.

[4] M. S. Pepe, H. Janes, G. Longton, W. Leisenring, and P. Newcomb, "Limitations of the odds ratio in gauging the performance of a diagnostic, prognostic, or screening marker," American Journal of Epidemiology, vol. 159, no. 9, pp. 882-890, 2004.

[5] H. Lan, H. Lu, X. Wang, and H. Jin, "MicroRNAs as potential biomarkers in cancer: opportunities and challenges," BioMed Research International, vol. 2015, Article ID 125094, 17 pages, 2015.

[6] J. Xu, Z. Cao, W. Liu et al., "Plasma miRNAs effectively distinguish patients with pancreatic cancer from controls: a multicenter study," Annals of Surgery, 2015. 
[7] H. Ding, Z. Huang, M. Chen et al., "Identification of a panel of five serum miRNAs as a biomarker for Parkinson's disease," Parkinsonism \& Related Disorders, vol. 22, pp. 68-73, 2015.

[8] S. C. Marques, M. B. Laursen, J. S. Bødker et al., "MicroRNAs in B-cells: from normal differentiation to treatment of malignancies," Oncotarget, vol. 6, no. 1, pp. 7-25, 2015.

[9] L. K. Jørgensen, M. Ø. Poulsen, M. B. Laursen et al., "MicroRNAs as novel biomarkers in diffuse large B-Cell lymphoma-a systematic review," Danish Medical Journal, vol. 62, no. 5, Article ID A5048, 2015.

[10] M. D. Jansson and A. H. Lund, "MicroRNA and cancer," Molecular Oncology, vol. 6, no. 6, pp. 590-610, 2012.

[11] H. Xue, L.-M. Hua, M. Guo, and J.-M. Luo, "SHIP1 is targeted by miR-155 in acute myeloid leukemia," Oncology Reports, vol. 32, no. 5, pp. 2253-2259, 2014.

[12] L. Huang, J. Luo, Q. Cai et al., "MicroRNA-125b suppresses the development of bladder cancer by targeting E2F3," International Journal of Cancer, vol. 128, no. 8, pp. 1758-1769, 2011.

[13] R. Mashima, "Physiological roles of miR-155," Immunology, vol. 145, no. 3, pp. 323-333, 2015.

[14] K. Musilova and M. Mraz, "MicroRNAs in B-cell lymphomas: how a complex biology gets more complex," Leukemia, vol. 29, no. 5, pp. 1004-1017, 2015.

[15] R. W. Georgantas III, R. Hildreth, S. Morisot et al., "CD34+ hematopoietic stem-progenitor cell microRNA expression and function: a circuit diagram of differentiation control," Proceedings of the National Academy of Sciences of the United States of America, vol. 104, no. 8, pp. 2750-2755, 2007.

[16] R. M. O’Connell, K. D. Taganov, M. P. Boldin, G. Cheng, and D. Baltimore, "MicroRNA-155 is induced during the macrophage inflammatory response," Proceedings of the National Academy of Sciences of the United States of America, vol. 104, no. 5, pp. 16041609, 2007.

[17] M. Ceppi, A. M. Pereira, I. Dunand-Sauthier et al., "MicroRNA155 modulates the interleukin-1 signaling pathway in activated human monocyte-derived dendritic cells," Proceedings of the National Academy of Sciences of the United States of America, vol. 106, no. 8, pp. 2735-2740, 2009.

[18] T.-H. Thai, D. P. Calado, S. Casola et al., "Regulation of the germinal center response by MicroRNA-155," Science, vol. 316, no. 5824, pp. 604-608, 2007.

[19] W. Zhang, J. He, F. Zhang et al., "Prognostic role of microRNA155 in various carcinomas: results from a meta-analysis," Disease Markers, vol. 34, no. 6, pp. 379-386, 2013.

[20] I. A. Babar, C. J. Cheng, C. J. Booth et al., "Nanoparticle-based therapy in an in vivo microRNA-155 (miR-155)-dependent mouse model of lymphoma," Proceedings of the National Academy of Sciences of the United States of America, vol. 109, no. 26, pp. E1695-E1704, 2012.

[21] A. Liberati, D. G. Altman, J. Tetzlaff et al., "The PRISMA statement for reporting systematic reviews and meta-analyses of studies that evaluate health care interventions: explanation and elaboration," PLoS Medicine, vol. 6, no. 7, Article ID e1000100, 2009.

[22] R. M. O’Connell, A. A. Chaudhuri, D. S. Rao, and D. Baltimore, "Inositol phosphatase SHIP1 is a primary target of miR-155," Proceedings of the National Academy of Sciences of the United States of America, vol. 106, no. 17, pp. 7113-7118, 2009.

[23] S. Costinean, S. K. Sandhu, I. M. Pedersen et al., "Src homology 2 domain-containing inositol-5-phosphatase and CCAAT enhancer-binding protein $\beta$ are targeted by miR-155 in B cells of $\mathrm{E} \mu$-MiR-155 transgenic mice," Blood, vol. 114, no. 7, pp. 13741382, 2009.

[24] G. Teng, P. Hakimpour, P. Landgraf et al., "MicroRNA-155 is a negative regulator of activation-induced cytidine deaminase," Immunity, vol. 28, no. 5, pp. 621-629, 2008.

[25] E. Vigorito, K. L. Perks, C. Abreu-Goodger et al., "microRNA155 regulates the generation of immunoglobulin class-switched plasma cells," Immunity, vol. 27, no. 6, pp. 847-859, 2007.

[26] L. N. Dagan, X. Jiang, S. Bhatt, E. Cubedo, K. Rajewsky, and I. S. Lossos, "miR-155 regulates HGAL expression and increases lymphoma cell motility," Blood, vol. 119, no. 2, pp. 513-520, 2012.

[27] D. Rai, S.-W. Kim, M. R. McKeller, P. L. M. Dahia, and R. C. T. Aguiar, "Targeting of SMAD5 links microRNA-155 to the TGF$\beta$ pathway and lymphomagenesis," Proceedings of the National Academy of Sciences of the United States of America, vol. 107, no. 7, pp. 3111-3116, 2010.

[28] E. Tili, J.-J. Michaille, A. Cimino et al., "Modulation of miR155 and miR-125b levels following lipopolysaccharide/TNF- $\alpha$ stimulation and their possible roles in regulating the response to endotoxin shock," The Journal of Immunology, vol. 179, no. 8, pp. 5082-5089, 2007.

[29] L.-F. Lu, T.-H. Thai, D. P. Calado et al., "Foxp3-dependent microRNA155 confers competitive fitness to regulatory T cells by targeting SOCS1 protein," Immunity, vol. 30, no. 1, pp. 80-91, 2009.

[30] L. H. Sehn, J. Donaldson, M. Chhanabhai et al., "Introduction of combined CHOP plus rituximab therapy dramatically improved outcome of diffuse large B-cell lymphoma in British Columbia," Journal of Clinical Oncology, vol. 23, no. 22, pp. 5027-5033, 2005.

[31] R. Vaidya and T. E. Witzig, "Prognostic factors for diffuse large B-cell lymphoma in the R(X)CHOP era," Annals of Oncology, vol. 25, no. 11, pp. 2124-2133, 2014.

[32] H. Zhong, L. Xu, J.-H. Zhong et al., "Clinical and prognostic significance of miR-155 and miR-146a expression levels in formalin-fixed/paraffin-embedded tissue of patients with diffuse large B-cell lymphoma," Experimental and Therapeutic Medicine, vol. 3, no. 5, pp. 763-770, 2012.

[33] C. H. Lawrie, J. Chi, S. Taylor et al., "Expression of microRNAs in diffuse large B cell lymphoma is associated with immunophenotype, survival and transformation from follicular lymphoma," Journal of Cellular and Molecular Medicine, vol. 13, no. 7, pp. 1248-1260, 2009.

[34] C. H. Lawrie, S. Soneji, T. Marafioti et al., "MicroRNA expression distinguishes between germinal center B cell-like and activated B cell-like subtypes of diffuse large B cell lymphoma," International Journal of Cancer, vol. 121, no. 5, pp. 1156-1161, 2007.

[35] C. H. Lawrie, S. Gal, H. M. Dunlop et al., "Detection of elevated levels of tumour-associated microRNAs in serum of patients with diffuse large B-cell lymphoma," British Journal of Haematology, vol. 141, no. 5, pp. 672-675, 2008.

[36] A. Roehle, K. P. Hoefig, D. Repsilber et al., "MicroRNA signatures characterize diffuse large B-cell lymphomas and follicular lymphomas," British Journal of Haematology, vol. 142, no. 5, pp. 732-744, 2008.

[37] C. Fang, D.-X. Zhu, H.-J. Dong et al., "Serum microRNAs are promising novel biomarkers for diffuse large B cell lymphoma," Annals of Hematology, vol. 91, no. 4, pp. 553-559, 2012.

[38] L. Di Lisio, M. Sánchez-Beato, G. Gómez-López et al., "MicroRNA signatures in B-cell lymphomas," Blood Cancer Journal, vol. 2, no. 2, article e57, 2012. 
[39] J. Iqbal, Y. Shen, X. Huang et al., "Global microRNA expression profiling uncovers molecular markers for classification and prognosis in aggressive B-cell lymphoma," Blood, vol. 125, no. 7, pp. 1137-1145, 2015.

[40] M. Zajdel, G. Rymkiewicz, M. Chechlinska et al., "miR expression in MYC-negative DLBCL/BL with partial trisomy 11 is similar to classical Burkitt lymphoma and different from diffuse large B-cell lymphoma," Tumor Biology, vol. 36, no. 7, pp. 53775388, 2015.

[41] A. A. Alizadeh, M. B. Elsen, R. E. Davis et al., "Distinct types of diffuse large B-cell lymphoma identified by gene expression profiling," Nature, vol. 403, no. 6769, pp. 503-511, 2000.

[42] C. P. Hans, D. D. Weisenburger, T. C. Greiner et al., "Confirmation of the molecular classification of diffuse large B-cell lymphoma by immunohistochemistry using a tissue microarray," Blood, vol. 103, no. 1, pp. 275-282, 2004.

[43] A. Rosenwald, G. Wright, W. C. Chan et al., "The use of molecular profiling to predict survival after chemotherapy for diffuse large-B-cell lymphoma," The New England Journal of Medicine, vol. 346, no. 25, pp. 1937-1947, 2002.

[44] W. W. L. Choi, D. D. Weisenburger, T. C. Greiner et al., "A new immunostain algorithm classifies diffuse large B-cell lymphoma into molecular subtypes with high accuracy," Clinical Cancer Research, vol. 15, no. 17, pp. 5494-5502, 2009.

[45] J. A. Read, J. L. Koff, L. J. Nastoupil, J. N. Williams, J. B. Cohen, and C. R. Flowers, "Evaluating cell-of-origin subtype methods for predicting diffuse large B-cell lymphoma survival: a metaanalysis of gene expression profiling and immunohistochemistry algorithms," Clinical Lymphoma, Myeloma and Leukemia, vol. 14, no. 6, pp. 460.e2-467.e2, 2014.

[46] S. Caramuta, L. Lee, D. M. Özata et al., "Role of microRNAs and microRNA machinery in the pathogenesis of diffuse large B-cell lymphoma," Blood Cancer Journal, vol. 3, no. 10, article e152, 2013.

[47] L. Fischer, M. Hummel, A. Korfel, D. Lenze, K. Joehrens, and E. Thiel, "Differential micro-RNA expression in primary CNS and nodal diffuse large B-cell lymphomas," Neuro-Oncology, vol. 13, no. 10, pp. 1090-1098, 2011.

[48] J. Kluiver, S. Poppema, D. de Jong et al., "BIC and miR-155 are highly expressed in Hodgkin, primary mediastinal and diffuse large B cell lymphomas," The Journal of Pathology, vol. 207, no. 2, pp. 243-249, 2005.

[49] J.-L. Robertus, G. Harms, T. Blokzijl et al., "Specific expression of miR-17-5p and miR-127 in testicular and central nervous system diffuse large B-cell lymphoma," Modern Pathology, vol. 22, no. 4, pp. 547-555, 2009.

[50] H. Huskova, K. Korecka, J. Karban et al., "Oncogenic microRNA-155 and its target PU.1: an integrative gene expression study in six of the most prevalent lymphomas," International Journal of Hematology, vol. 102, no. 4, pp. 441-450, 2015.

[51] P. S. Eis, W. Tam, L. Sun et al., "Accumulation of miR-155 and BIC RNA in human B cell lymphomas," Proceedings of the National Academy of Sciences of the United States of America, vol. 102, no. 10, pp. 3627-3632, 2005.

[52] H. Go, J.-Y. Jang, P.-J. Kim et al., "MicroRNA-21 plays an oncogenic role by targeting FOXO1 and activating the PI3K/AKT pathway in diffuse large B-cell lymphoma," Oncotarget, vol. 6, no. 17, pp. 15035-15049, 2015.

[53] J. Imig, N. Motsch, J. Y. Zhu et al., "microRNA profiling in Epstein-Barr virus-associated B-cell lymphoma," Nucleic Acids Research, vol. 39, no. 5, pp. 1880-1893, 2011.
[54] J. Tuo, D. Shen, H. H. Yang, and C.-C. Chan, "Distinct MicroRNA-155 expression in the vitreous of patients with primary vitreoretinal lymphoma and uveitis," American Journal of Ophthalmology, vol. 157, no. 3, pp. 728-734, 2014.

[55] T. Zhang, K. Nie, and W. Tam, "BIC is processed efficiently to microRNA-155 in Burkitt lymphoma cells," Leukemia, vol. 22, no. 9, pp. 1795-1797, 2008.

[56] J. Kluiver, E. Haralambieva, D. De Jong et al., "Lack of BIC and microRNA miR-155 expression in primary cases of Burkitt lymphoma," Genes Chromosomes and Cancer, vol. 45, no. 2, pp. 147-153, 2006.

[57] M. Metzler, M. Wilda, K. Busch, S. Viehmann, and A. Borkhardt, "High expression of precursor MicroRNA-155/BIC RNA in children with burkitt lymphoma," Genes Chromosomes and Cancer, vol. 39, no. 2, pp. 167-169, 2004.

[58] K. Jones, J. P. Nourse, C. Keane, A. Bhatnagar, and M. K. Gandhi, "Plasma microRNA are disease response biomarkers in classical hodgkin lymphoma," Clinical Cancer Research, vol. 20, no. 1, pp. 253-264, 2014.

[59] C. Thorns, J. Kuba, V. Bernard et al., "Deregulation of a distinct set of microRNAs is associated with transformation of gastritis into MALT lymphoma," Virchows Archiv, vol. 460, no. 4, pp. 371-377, 2012.

[60] J. Cai, X. Liu, J. Cheng et al., "MicroRNA-200 is commonly repressed in conjunctival MALT lymphoma, and targets cyclin E2," Graefe's Archive for Clinical and Experimental Ophthalmology, vol. 250, no. 4, pp. 523-531, 2012.

[61] Y. Saito, H. Suzuki, H. Tsugawa et al., "Overexpression of miR142-5p and miR-155 in gastric mucosa-associated lymphoid tissue (MALT) lymphoma resistant to Helicobacter pylori eradication," PLoS ONE, vol. 7, no. 11, Article ID e47396, 2012.

[62] Y. Takei, N. Ohnishi, M. Kisaka, and K. Mihara, "Determination of abnormally expressed microRNAs in bone marrow smears from patients with follicular lymphomas," SpringerPlus, vol. 3, article 288, 2014.

[63] J. Peveling-Oberhag, G. Crisman, A. Schmidt et al., "Dysregulation of global microRNA expression in splenic marginal zone lymphoma and influence of chronic hepatitis $\mathrm{C}$ virus infection," Leukemia, vol. 26, no. 7, pp. 1654-1662, 2012.

[64] A. J. Arribas, C. Gómez-Abad, M. Sánchez-Beato et al., "Splenic marginal zone lymphoma: comprehensive analysis of gene expression and miRNA profiling," Modern Pathology, vol. 26, no. 7, pp. 889-901, 2013.

[65] M. Bouteloup, A. Verney, N. Rachinel et al., "MicroRNA expression profile in splenic marginal zone lymphoma," British Journal of Haematology, vol. 156, no. 2, pp. 279-281, 2012.

[66] C. H. Lawrie, E. Ballabio, O.-J. Dyar et al., "MicroRNA expression in chronic lymphocytic leukaemia," British Journal of Haematology, vol. 147, no. 3, pp. 398-402, 2009.

[67] D.-X. Zhu, W. Zhu, C. Fang et al., "MiR-181a/b significantly enhances drug sensitivity in chronic lymphocytic leukemia cells via targeting multiple anti-apoptosis genes," Carcinogenesis, vol. 33, no. 7, pp. 1294-1301, 2012.

[68] S. Marton, M. R. Garcia, C. Robello et al., "Small RNAs analysis in CLL reveals a deregulation of miRNA expression and novel miRNA candidates of putative relevance in CLL pathogenesis," Leukemia, vol. 22, no. 2, pp. 330-338, 2008.

[69] Y. Y. Yeh, H. G. Ozer, A. M. Lehman et al., "Characterization of CLL exosomes reveals a distinct microRNA signature and enhanced secretion by activation of BCR signaling," Blood, vol. 125, no. 21, pp. 3297-3305, 2015. 
[70] K. Vargova, N. Curik, P. Burda et al., "MYB transcriptionally regulates the miR-155 host gene in chronic lymphocytic leukemia," Blood, vol. 117, no. 14, pp. 3816-3825, 2011.

[71] C. P. Pallasch, M. Patz, Y. Jung Park et al., "miRNA deregulation by epigenetic silencing disrupts suppression of the oncogene PLAG1 in chronic lymphocytic leukemia," Blood, vol. 114, no. 15, pp. 3255-3264, 2009.

[72] S. Li, H. F. Moffett, J. Lu et al., "Microrna expression profiling identifies activated B cell status in chronic lymphocytic leukemia cells," PLoS ONE, vol. 6, no. 3, Article ID e16956, 2011.

[73] V. Fulci, S. Chiaretti, M. Goldoni et al., "Quantitative technologies establish a novel microRNA profile of chronic lymphocytic leukemia," Blood, vol. 109, no. 11, pp. 4944-4951, 2007.

[74] A. Ferrajoli, T. D. Shanafelt, C. Ivan et al., "Prognostic value of miR-155 in individuals with monoclonal B-cell lymphocytosis and patients with B chronic lymphocytic leukemia," Blood, vol. 122, no. 11, pp. 1891-1899, 2013.

[75] I. Jung and R. C. T. Aguiar, "MicroRNA-155 expression and outcome in diffuse large B-cell lymphoma," British Journal of Haematology, vol. 144, no. 1, pp. 138-140, 2009.

[76] T. L. Parker and M. P. Strout, "Chronic lymphocytic leukemia: prognostic factors and impact on treatment," Discovery Medicine, vol. 11, no. 57, pp. 115-123, 2011.

[77] R. Visone, L. Z. Rassenti, A. Veronese et al., "Karyotype-specific microRNA signature in chronic lymphocytic leukemia," Blood, vol. 114, no. 18, pp. 3872-3879, 2009.

[78] S. Rossi, M. Shimizu, E. Barbarotto et al., "MicroRNA fingerprinting of CLL patients with chromosome 17p deletion identify a miR-21 score that stratifies early survival," Blood, vol. 116, no. 6, pp. 945-952, 2010.

[79] D. Guinn, A. S. Ruppert, K. Maddocks et al., "miR-155 expression is associated with chemoimmunotherapy outcome and is modulated by Bruton's tyrosine kinase inhibition with Ibrutinib," Leukemia, vol. 29, no. 5, pp. 1210-1213, 2015.

[80] M. Wang, L. P. Tan, M. K. Dijkstra et al., "miRNA analysis in Bcell chronic lymphocytic leukaemia: proliferation centres characterized by low miR-150 and high BIC/miR-155 expression," The Journal of Pathology, vol. 215, no. 1, pp. 13-20, 2008.

[81] B. Cui, L. Chen, S. Zhang et al., "Micro RNA-155 influences Bcell receptor signaling and associates with aggressive disease in chronic lymphocytic leukemia," Blood, vol. 124, no. 4, pp. 546554, 2014.

[82] A. E. Rodriguez, J. A. Hernandez, M. Hernandez et al., "Chronic lymphocytic leukemia (CLL) with a high number of losses in 13Q is associated with different biological features," Laboratory Investigation, vol. 93, article 358A, 2013.

[83] B. Eichhorst, T. Robak, E. Montserrat et al., "Chronic lymphocytic leukaemia: ESMO Clinical Practice Guidelines for diagnosis, treatment and follow-up," Annals of Oncology, vol. 26, supplement 5, Article ID mdv303, pp. v50-v54, 2015.

[84] A. Ruskoné-Fourmestraux, A. Lavergne, P. H. Aegerter et al., "Predictive factors for regression of gastric MALT lymphoma after anti-Helicobacter pylori treatment," Gut, vol. 48, no. 3, pp. 297-303, 2001.

[85] Y. Zhang, A. M. Roccaro, C. Rombaoa et al., "LNA-mediated anti-miR-155 silencing in low-grade B-cell lymphomas," Blood, vol. 120, no. 8, pp. 1678-1686, 2012.

[86] M. M. Fabani, C. Abreu-Goodger, D. Williams et al., "Efficient inhibition of miR-155 function in vivo by peptide nucleic acids," Nucleic Acids Research, vol. 38, no. 13, pp. 4466-4475, 2010.
[87] C. J. Cheng, R. Bahal, I. A. Babar et al., "MicroRNA silencing for cancer therapy targeted to the tumour microenvironment," Nature, vol. 518, no. 7537, pp. 107-110, 2015.

[88] J. H. Kim, W. S. Kim, and C. Park, "Epstein-Barr virus latent membrane protein-1 protects B-cell lymphoma from rituximabinduced apoptosis through miR-155-mediated Akt activation and up-regulation of Mcl-1," Leukemia and Lymphoma, vol. 53, no. 8, pp. 1586-1591, 2012.

[89] D. Rai, S. Karanti, I. Jung, P. L. M. Dahia, and R. C. T. Aguiar, "Coordinated expression of microRNA-155 and predicted target genes in diffuse large B-cell lymphoma," Cancer Genetics and Cytogenetics, vol. 181, no. 1, pp. 8-15, 2008.

[90] H. D. Munch-Petersen, U. Ralfkiaer, L. D. Sjö et al., "Differential expression of miR-155 and miR-21 in tumor and stroma cells in diffuse large B-Cell lymphoma," Applied Immunohistochemistry and Molecular Morphology, vol. 23, no. 3, pp. 188-195, 2015.

[91] A. E. Rodríguez, J. Á. Hernández, R. Benito et al., "Molecular characterization of chronic lymphocytic leukemia patients with a high number of losses in 13q14," PLoS ONE, vol. 7, no. 11, Article ID e48485, 2012.

[92] G. A. Calin, M. Ferracin, A. Cimmino et al., "A microRNA signature associated with prognosis and progression in chronic lymphocytic leukemia," The New England Journal of Medicine, vol. 353, no. 17, pp. 1793-1801, 2005.

[93] J. Li, P. Smyth, R. Flavin et al., "Comparison of miRNA expression patterns using total RNA extracted from matched samples of formalin-fixed paraffin-embedded (FFPE) cells and snap frozen cells," BMC Biotechnology, vol. 7, article 36, 2007.

[94] M. S. Pepe, R. Etzioni, Z. Feng et al., "Phases of biomarker development for early detection of cancer," Journal of the National Cancer Institute, vol. 93, no. 14, pp. 1054-1061, 2001.

[95] National Library of Medicine (US), "Trametinib and Akt inhibitor GSK2141795 in treating patients with acute myeloid leukemia," ClinicalTrials.gov, National Library of Medicine (US), Bethesda, Md, USA, 2015.

[96] miRagen Therapeutics, "Safety, tolerability and pharmacokinetic study of MRG-106 in patients with cutaneous $\mathrm{T}$ cell lymphoma (CTCL), MF subtype," in ClinicalTrials.gov, National Library of Medicine (US), Bethesda, Md, USA, 2015.

[97] E. S. Hildebrandt-Eriksen, Y. Z. Bagger, T. B. Knudsen et al., "A unique therapy for HCV inhibits microRNA-122 in humans and results in HCV RNA suppression in chronically infected chimpanzees: results from primate and first-in-human studies," Hepatology, vol. 50, no. 6, p. LB19, 2009.

[98] V. Manfè, E. Biskup, A. Rosbjerg et al., "MiR-122 regulates p53/Akt signalling and the chemotherapy-induced apoptosis in cutaneous T-cell lymphoma," PLoS ONE, vol. 7, no. 1, Article ID e29541, 2012. 

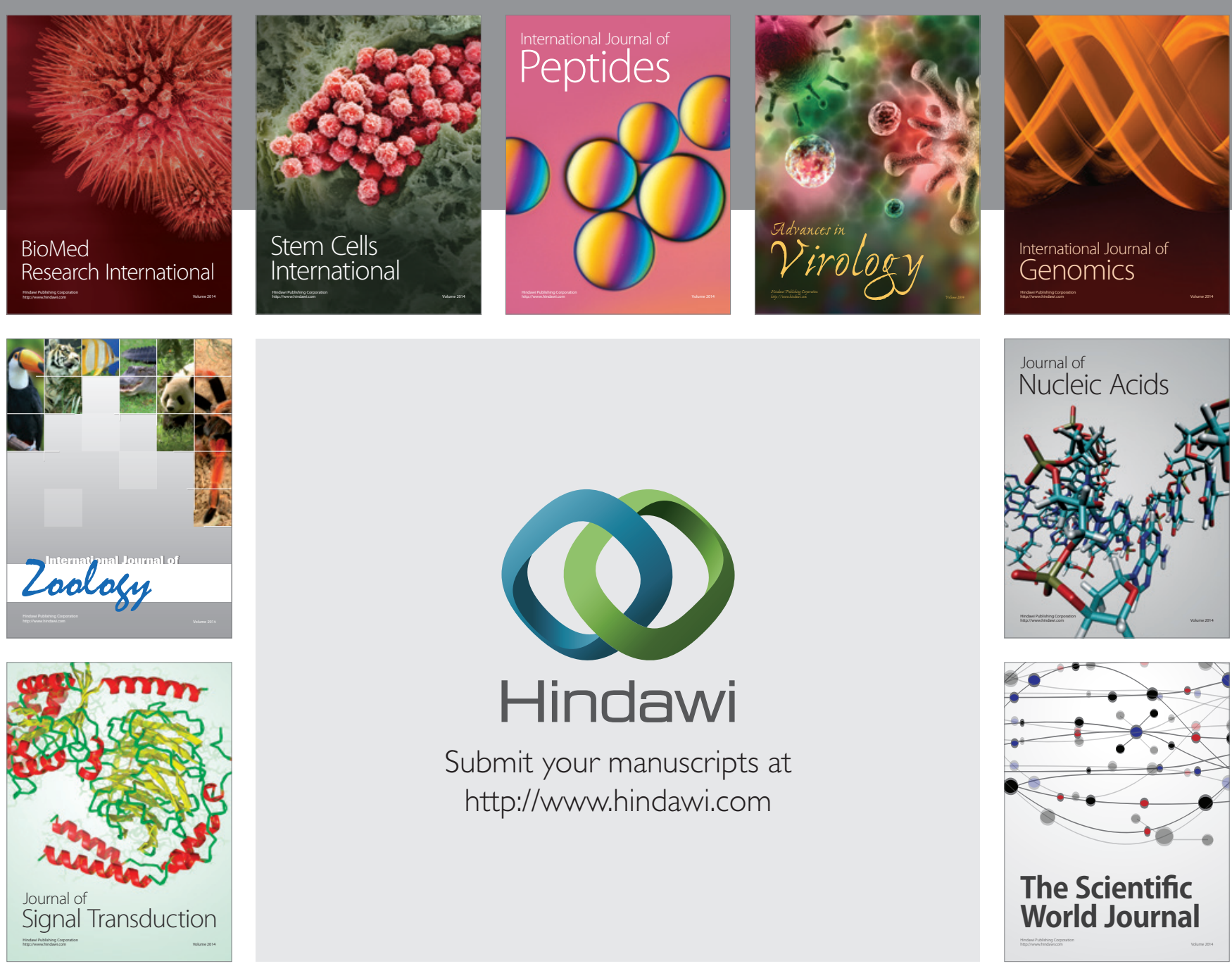

Submit your manuscripts at

http://www.hindawi.com
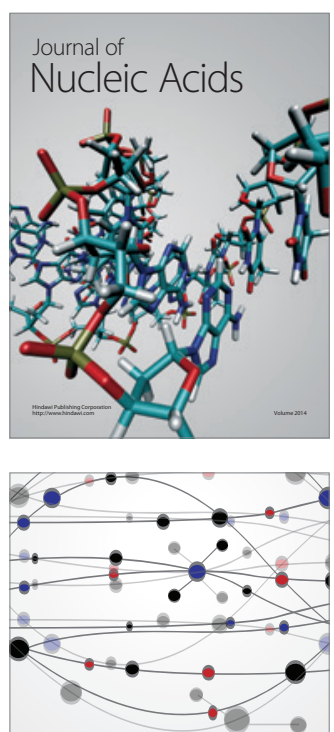

The Scientific World Journal
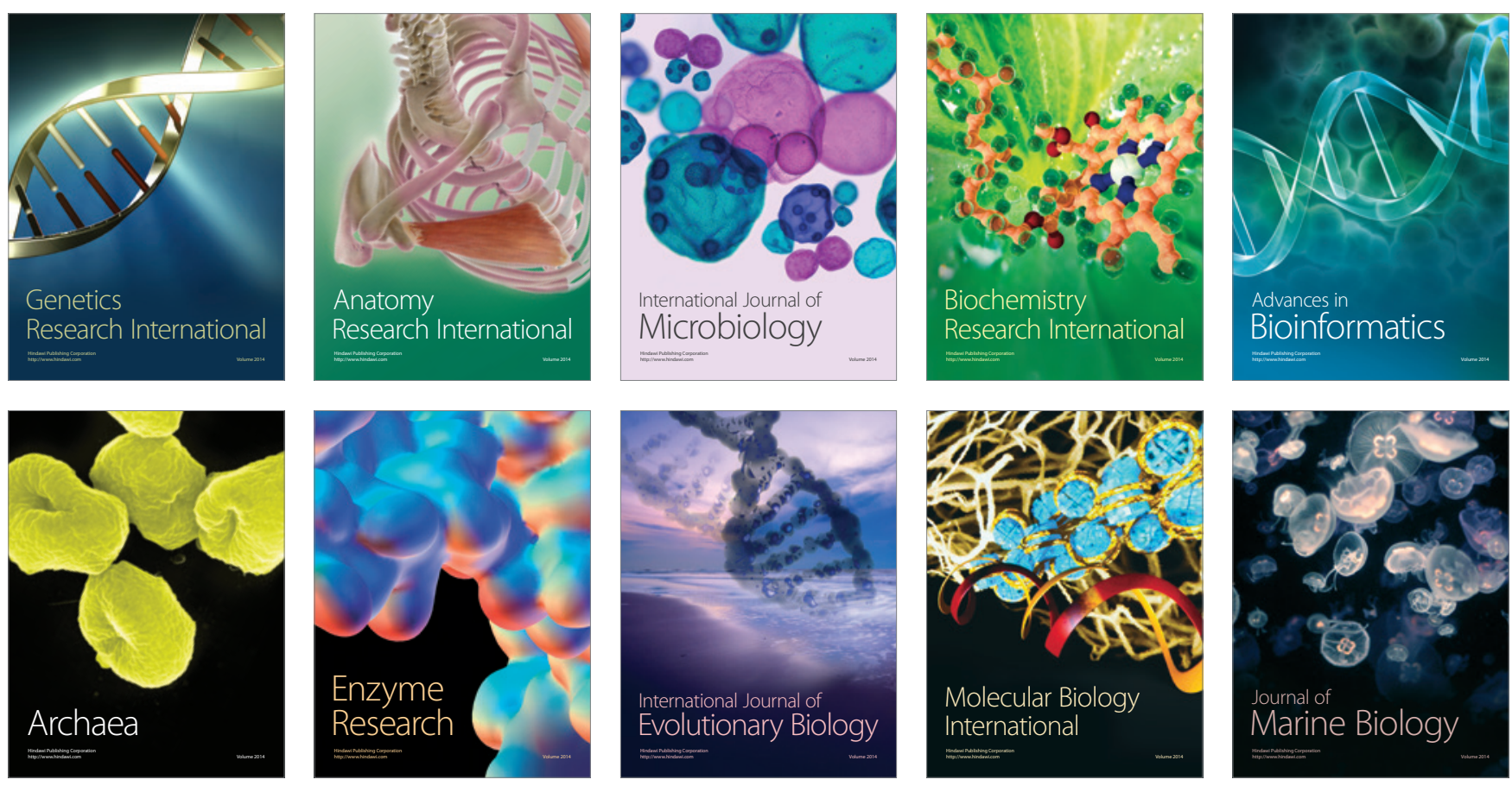